\title{
APPLICATION OF ELECTRICAL RESISTIVITY TOMOGRAPHY TO THE DETECTION OF THE ERMAKIA (NORTHERN GREECE) CAVITY SYSTEM
}

\author{
Vargemezis G. ${ }^{1}$, Tsourlos P. ${ }^{1}$, Papazachos C. ${ }^{1}$, and Kostopoulos D. ${ }^{2}$ \\ ${ }^{1}$ Aristotle University of Thessaloniki, School of Geology, Department of Geophysics, \\ varge@geo.auth.g,r,tsourlos@geo.auth.gr,kpapaza@geo.auth,gr, \\ ${ }^{2}$ Aristotle University of Thessaloniki, School of Geology, Department of Geology,
}

\begin{abstract}
Electrical resistivity tomography has been applied for the exploration of a karstic cave system at the region of Ermakia, next to the city of Ptolemais (NWt Greece). Geological investigations indicated that the main known Ermakia cave chamber "communicates" with at least one underground karstic ovoid. This evidence lead us to prospect the surrounding area by applying 2-D Electrical tomography survey on a regular grid in both $x, y$ directions. Survey lines crossed the known cave in order to verify $k$ the suitability of the method at the specific area and calibrate the resistivity values. Resistivity data were inverted and results were compiled in qusi3-D resistivity images. The interpreted results indicated the existence of two more chambers next to the known one which is in agreement with in-situ observations.
\end{abstract}

Key words: Electric tomography, seismic refraction tomography, cave mapping.

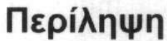

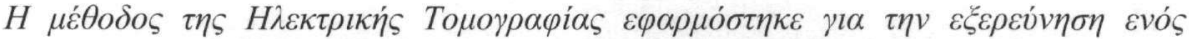

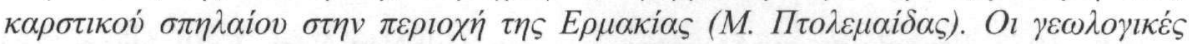

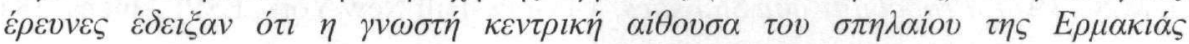

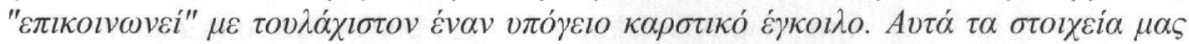

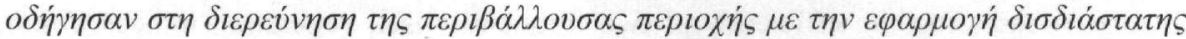

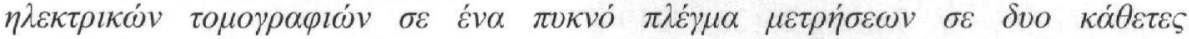

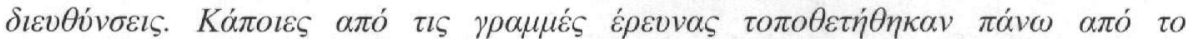

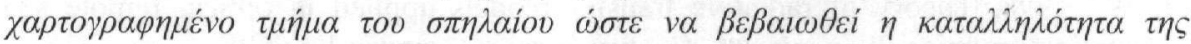

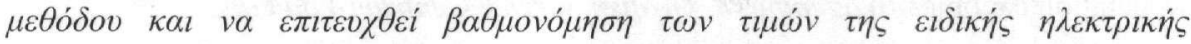

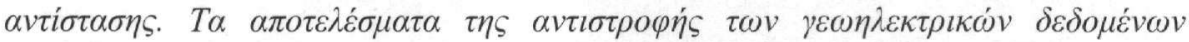
$\sigma v v \delta v \alpha \dot{\sigma \tau \eta \eta \kappa \alpha v ~ \omega ́ \sigma \tau \varepsilon ~ v \alpha ~ \pi \alpha \rho \alpha \chi \theta o v ́ v ~ \psi \varepsilon v \delta o \tau \rho l \sigma \delta i \alpha ́ \sigma \tau \alpha \tau \varepsilon \varsigma ~ \varepsilon l \kappa o ́ v \varepsilon \varsigma ~ \tau \eta ऽ ~ \alpha v \tau i ́ \sigma \tau \alpha \sigma \eta \varsigma . ~} H$

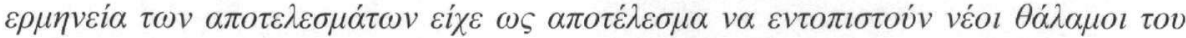

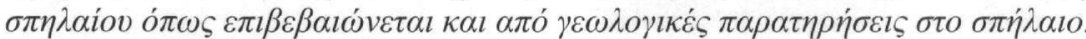

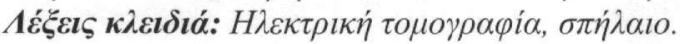

\section{Introduction}

Locating and accessing natural cavities by site investigation is usually a difficult and expensive task. Most of the surface geophysical methods can be successfully applied to detecting cavities 
(McCann et al. 1987). Although, in some cases no conclusive-reliable results can be obtained by the use of geophysical methods the potential cost savings compared to other methods render their use appealing.

Several case studies of successful application of geophysical techniques in cavity detection are presented in literature. Among them, the use of microgravity (Styles et al. 2005), GPR (Cahmberlain et al. 2003), and seismic (Nath 2004) techniques has been reported. They can give important information about buried structures such as of archaeological interest, or, physical or artificial voids. Since, there is no single geophysical method that proves to be optimum across all site characterization needs; it is quite common to use more than one technique to improve the reliability of the produced interpretations. Several successful integrated geophysical studies using more than one geophysical techniques have been reported in literature regarding cavity detection and mapping (Pirro et al. 2001, Cardarelli 2003, El-Quady et al. 2005, Gibson et al. 2004, Leucci and De Giorgi 2005).

Among the commonly used geophysical techniques, the geoelectrical method is the most popular (Zhou et al. 2004, Santos and Alfonso 2005) and has been successfully applied for the determination of the structural setting of cave systems. It's success is based on the resistivity contrast between the target (void) and the surrounding formation. Systematic geoelectrical measurements and advanced interpretation techniques results into reliable 2D and 3D images of the subsurface which can be easily understood and evaluated by non-geophysicists

In the present case, a cave formed in a limestone formation that has been discovered at the area of Ermakia (Kozani) is examined (Fig. 1). This cave consists of two champers and the total length exhibits 50 meters. The interest is about the possible existence of more chambers that could be explored. The application of electrical resistivity tomography technique was decided, to detect and map the cave system in a non-destructive and low cost way.

\section{Ermakia cave}

The cave of Ermakia is a small karstic formation, located in NW Greece, about $20 \mathrm{Km}$ N-NE of the city of Ptolemaida (Fig. 1). Ermakia Cave Poject (ECP) has been realized by the Department of Geography of the Aegean University after assignment by the Municipality of Agia Paraskevi (Prefecture of Kozani), where it administratively belongs.

The cave is placed in the foot of a small calcareous hill with a maximum altitude of about $966 \mathrm{~m}$. From a geological point of view, the locality take part of the western margin of the Pelagonian geotectonic zone which is represented in the area by the Maestrichtian Flysch and the Lower Cretaceous Tectonic Nappe of Vermion, consisted of calcareous conglomerates and dark-colored limestones (I.G.M.E. Map 1:50.000). Moreover, unconsolidated sands and breccia-conglomerates of Late Pleistocene and Holocene age partly cover the earlier lithostratigraphic units. The thickness of the limestone in the area doesn't overpasses $200 \mathrm{~m}$.

Ermakia cave is a young tectono-karstic void (opening) resulted from the combination of karstic erosion and tectonic stress on the Cretaceous limestones where it is sited. According to orientation, three kinds of discontinuities can be observed on the surface. A N-S one which mainly represents both limestone bedding and normal faults and a NW-SE to WNW-ESE which represents a well developed joint system. The main tectonic element, however, is a normal fault of N-S orientation and WSW dip, along which the main cave chambers are formed. The limestone appears strongly stressed in the eastern part of this fault while it is more massive and well bedded to the west. Observations into the cave indicate a relatively low presence of speleothems (pendant, wall and floor type deposits) in accordance to the estimated late Pleistocene-Holocene age of the opening. Two main chambers can be recognized into the cave: the first one to the south, where the natural entrance is placed and the second and larger one, to the north (main chamber). Between them a narrow corridor is formed along the main N-S fault. In situ investigations show that Ermakia cave 
must "communicate" with at least one more underground karstic ovoid, developed towards the East. This evidence allows us to prospect the enlarged area applying geophysical methods.

\section{ERT survey parameters}

The aim of the ERT survey was to detect and map any cavity that could be related to the existing cave. This required designing a systematic grid of measurement lines to obtain 2D ERT measurements in both $\mathrm{X}$ and $\mathrm{Y}$ directions (Fig. 2). This allowed the combination of $2 \mathrm{D}$ results to produce quasi-3D images of the subsurface, which are more informative than isolated 2D lines.

Measurements were obtained using the dipole-dipole array chosen due to its known good lateral resolution which is important when trying to locate isolated targets (viz. voids). The known limitation of the array concerning the signal-to-noise ratio was not a problem in this case, given the very high resistivities expected in a limestone environment.

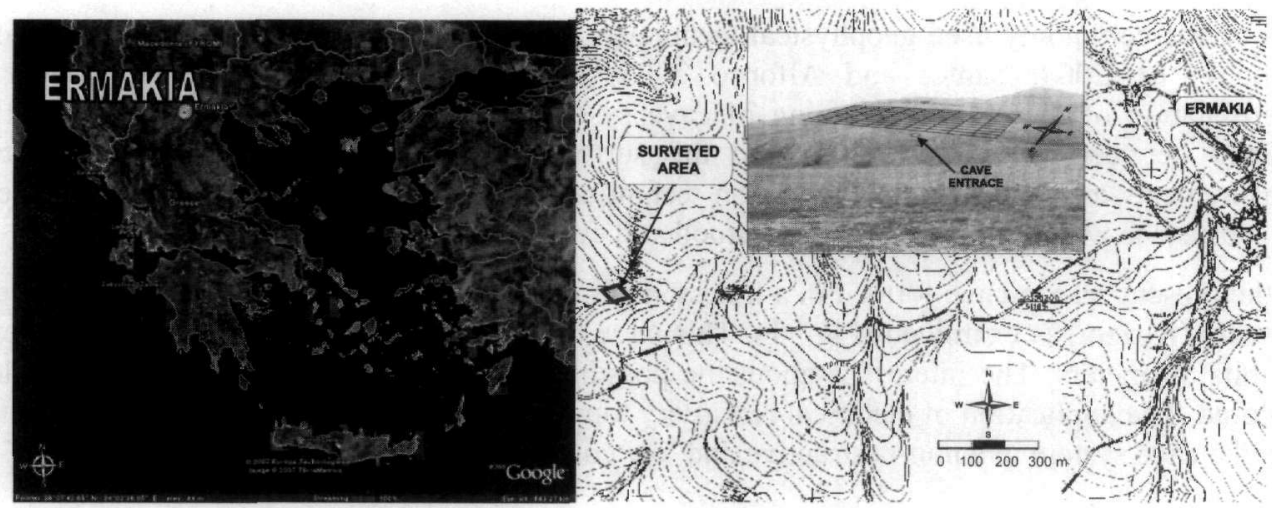

Figure 1 - Map of the study area with a photograph depicting the cave entrance and the geophysical measurement grid

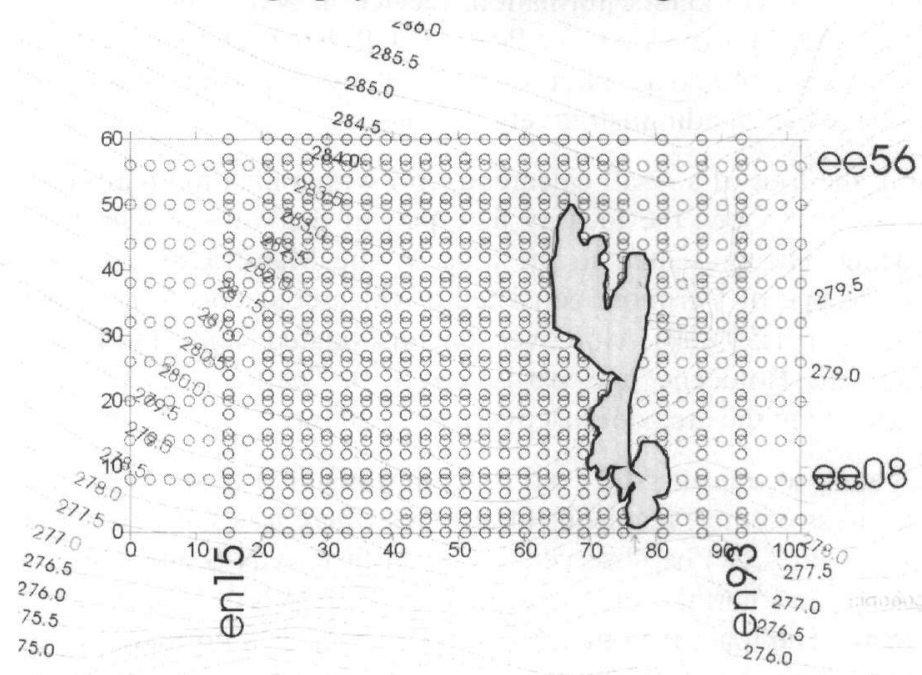

Figure 2 - The electrical tomography measurements grid (circles represent electrode positions)

A grid having dimensions $60 \times 106$ meters has been designed to be over the known cave but also extends to the west towards the area that there were indications of existing voids as suggested by the cave inspection. Ten (10) profiles of East-West direction have been conducted, and twenty three (23) profiles have been measured to the North-South direction (Fig. 2). The profiles are 
named after their orientation and position. The first letter (e) refers to Ermakia, the second (e or $n$ ) to the orientation (east or north) and the number at the end shows the position (in meters) referenced to the Southwest corner of the grid (point 0,0 ). In the first place the distance between the profiles was six (6) meters, yet at a later stage and it has been decreased to three (3) meters. The distance between the electrodes was $\mathrm{a}=3 \mathrm{~m}$ and the maximum dipole separation $\mathrm{N}_{\max }$ was $10 \mathrm{a}$ $(30 \mathrm{~m})$. These parameters were selected as a compromise between desired investigation depth and lateral resolution.

\section{Data processing}

In an initial stage, mapping of the raw data has been done in order to check data-quality and reject noisy measurements. The second step was to process data using a 2-D inversion algorithm. In this work a flexible non-linear 2-D scheme (Tsourlos 1995, Tsourlos et al. 1998) based on smoothness constrained algorithm was used to invert the collected resistivity data. The aim of the inversion is to construct an estimate of a subsurface resistivity distribution, which is consistent with the experimental data. The algorithm is iterative and fully automated and is based on a reliable 2.5D finite element forward modeling scheme, which is also used for calculating the Jacobian matrix when necessary. The results of the inversion are considered to be reliable since the RMS error for each inversion varied between 4-8 \%.

A typical inversion result of the second 2D East-West section (inversion RMS $2 \%$ ) is shown in Fig. 3c. The measured and calculated apparent resistivity pseudosections are depicted respectively in Fig. $3 \mathrm{a}$ and Fig. $3 \mathrm{~b}$ and are in close agreement.

In Fig. 3C. one can see two areas of high resistivity values. The first one is located at the center of the tomography, between 45-55 meters. This anomaly corresponds to the known cave. The second high resistivity starts approximately at the tenth meter of the section and ends at 20 meter and is positioned deeper than the first one. The "ceiling" of the anomaly lays at 5 meters and the "floo" at 10 meters below surface. Given the quite similar range of resistivity that this anomaly exhibits, compared to the known cave, it is quite possible to correspond to another cavity.

The above results in comparison with the existing cave demonstrate the effectiveness of the method to the detection of cavities in the specific area. Cavities are shown as geoelectric anomalies with very high resistivity $\left(>10^{5} \mathrm{Ohm}-\mathrm{m}\right)$.

In Figure 4, nine parallel inverted resistivity sections are depicted corresponding to East-West profiles while in Figure 5 the parallel North-South inverted resistivity sections are depicted. It is evident that there are numerous areas exhibiting high resistivities which can be interpreted as voids.

In an attempt to visualize the results better and since all 2D inversion results were produced using similar parameterization scheme all inverted sections (10 EW, $23 \mathrm{NS}$ ) were combined to form a quasi-3D images. In Figure 6 extracted resistivity slices for various depths are depicted together with the outline of the known cave. The existing cave is shown clearly at the depth slice from the depth of 6.5 meters until the depth of 14 meters covering an area of approximately $20 \times 30$ meters. Further, high resistivity anomalies are observed: at the layers of $6.5,8$ and 10.5 meters at the position of $X=10, Y=5$, at $X=15, Y=50$ at the depth from 8 up to 14 meters. These anomalies are considered to be probable cavities.

\section{Interpretation}

According to the interpreted data and the calibration with the existing cave, three main resistivity ranges were identified to classify the subsurface as low, medium and high resistivity as desctibed in Table 1. The last classification corresponds to areas interpreted as voids - cavities. According to 
this classification, a new gray scale has been determined and in Figure 8 3D the images of high resistivity areas (viz. possible caves) are depicted and are marked with letters (A to E).

The existing cave (marked as A in Fig. 8) is well defined. The geometric specifications of the target agree satisfactory with the dimensions of the cave as it is known from mapping. Further existing high resistivity areas are discussed below:

A. Raw Data Pseudosection

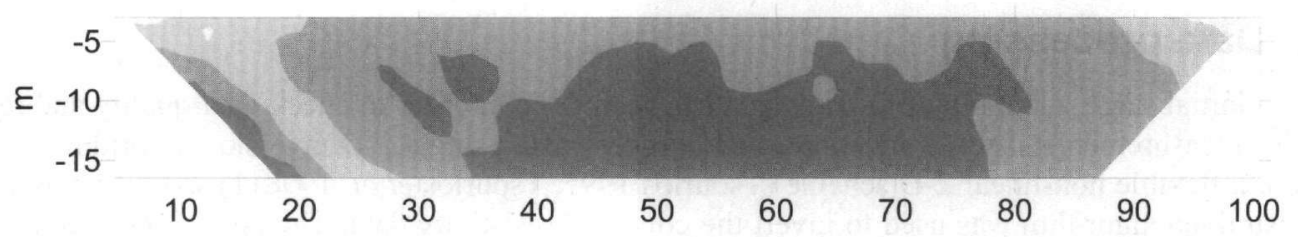

B. Pseudosection of synthetic data that correspond to model C

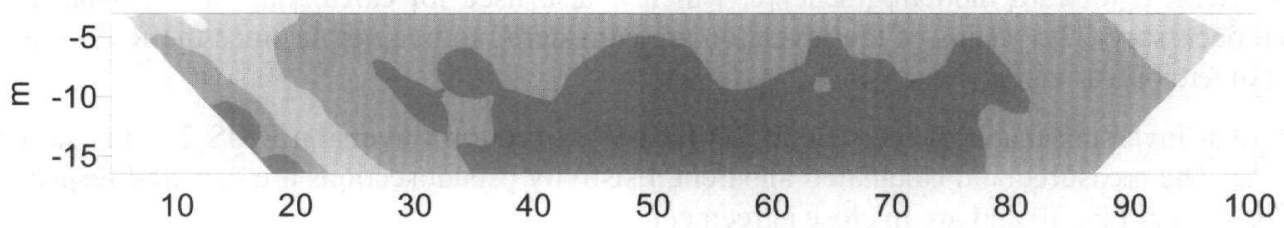

C. Geoelectrical model that the inversion resulted

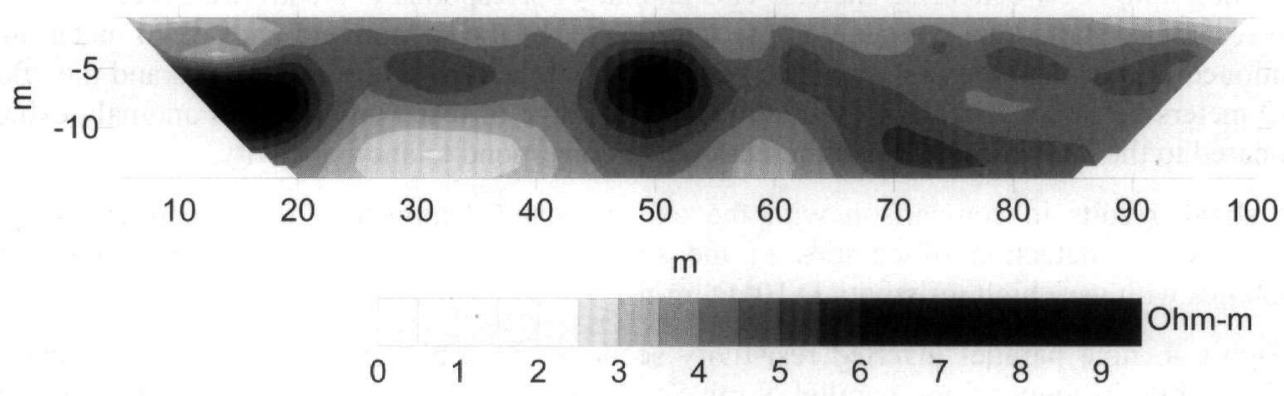

Figure 3 - Processed results of electrical tomography ee03: (a) measured data pseudosection, (b) calculated data pseudosection, (c) final inverted resistivity section

Table 1- Resistivity range and the corresponding interpretation

\begin{tabular}{|l|l|l|}
\hline \multicolumn{2}{|l|}{ RESISTIVITY VARIATION } & \multirow{2}{*}{ DESCRIPTION } \\
\cline { 1 - 2 }$(\mathbf{O h m}-\mathbf{m})$ & $\log ($ Ohm-m) & \\
\hline $10^{1}-10^{3}$ & $1-3$ & LOW RESISTIVITY AREA \\
\hline $10^{3}-10^{5}$ & $3-5$ & MEDIUM RESISTIVITY AREA \\
\hline$>10^{5}$ & $>5$ & POSSIBLE EXISTENCE OF CAVES RISTIVITY AREA \\
\hline
\end{tabular}




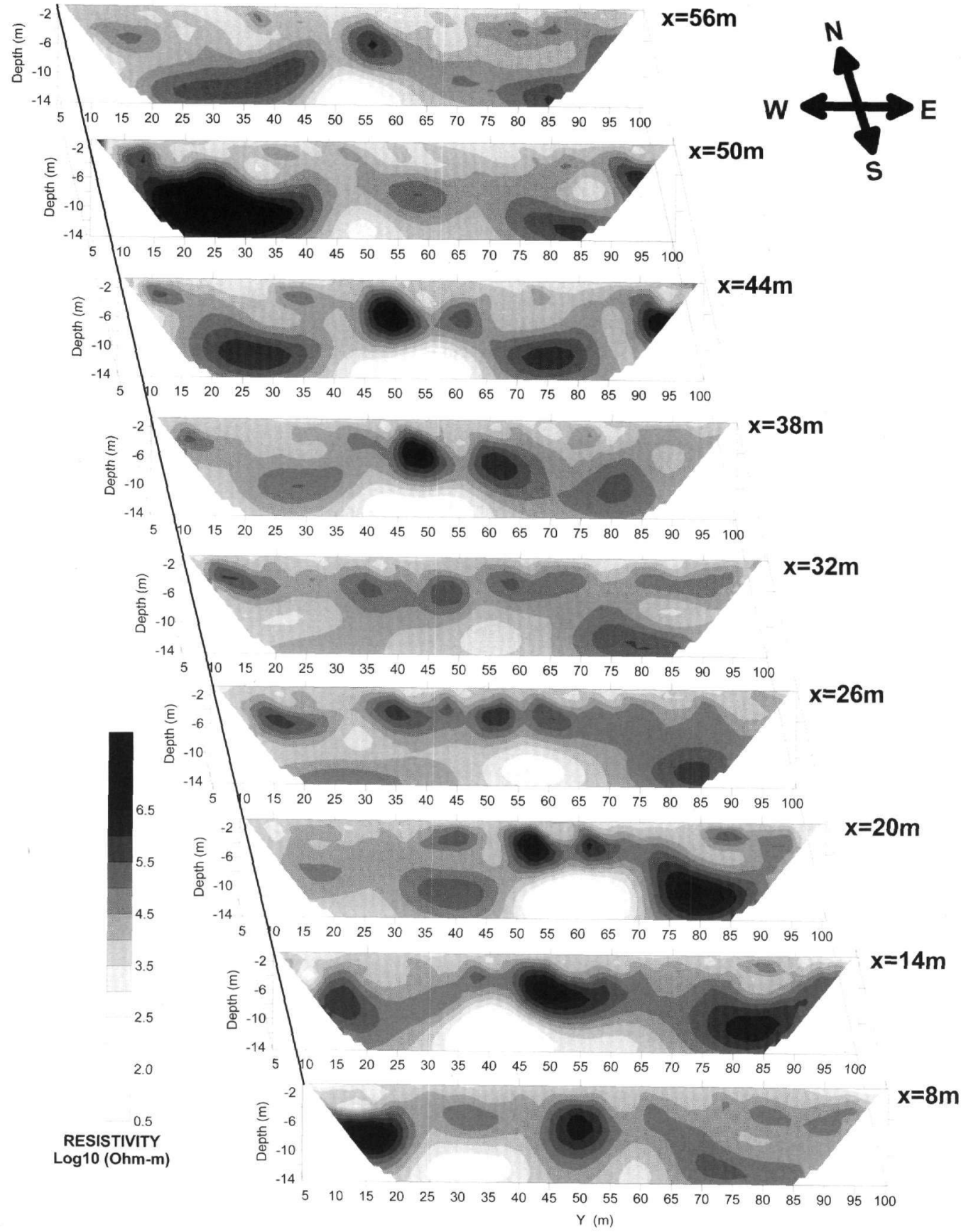

Figure 4 - Inverted resistivity sections of parallel East-West measurement lines 

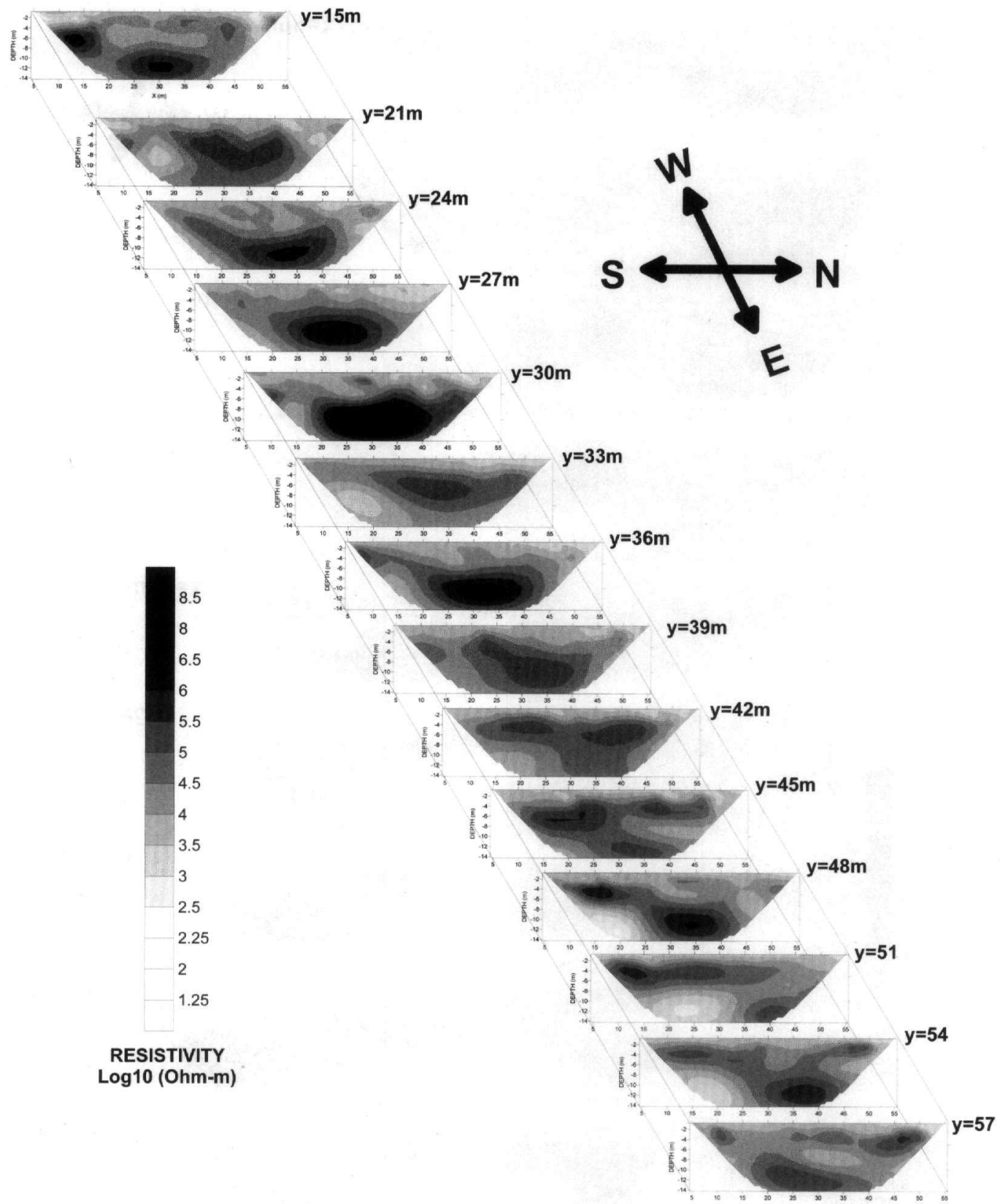

Figure 5 - Inverted resistivity sections of parallel South-North measurement lines

B: It is located at the west side of the existing cave at a distance of 10 meters at the depth of 4 meters. It is about an elongated structure, 20 meters long and 5 meters width. The mean height is about 2 meters. It is possible that it communicates with the easting cavity at the point having coordinates X60-Y20 of the grid at the depth of 6 meters.

C-c1: It is located north-northwest of the anomaly B. It consists from a major structure (C) whereas it is also possible that it is connected with a smaller structure (c1) at a depth of 10 meters. The length of the East-West dimension is about 15 meters and the North-South dimention has a length of 10 meters. The ceiling is at 8 meters depth and its height is 5 meters. 


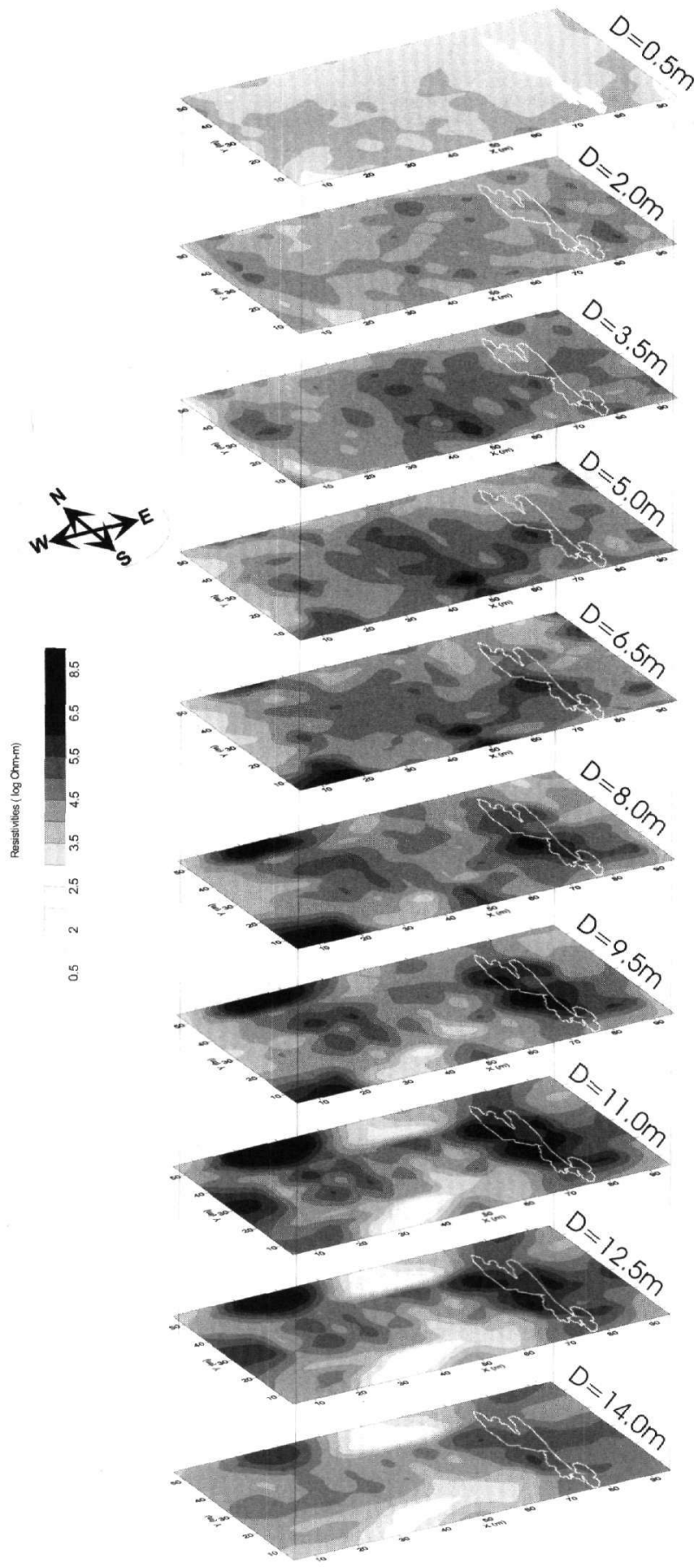

Figure 6 - Depth slices of the inverted resistivity data produced after combining all 2D inverted sections. The location of the known cave is noted with the white line 

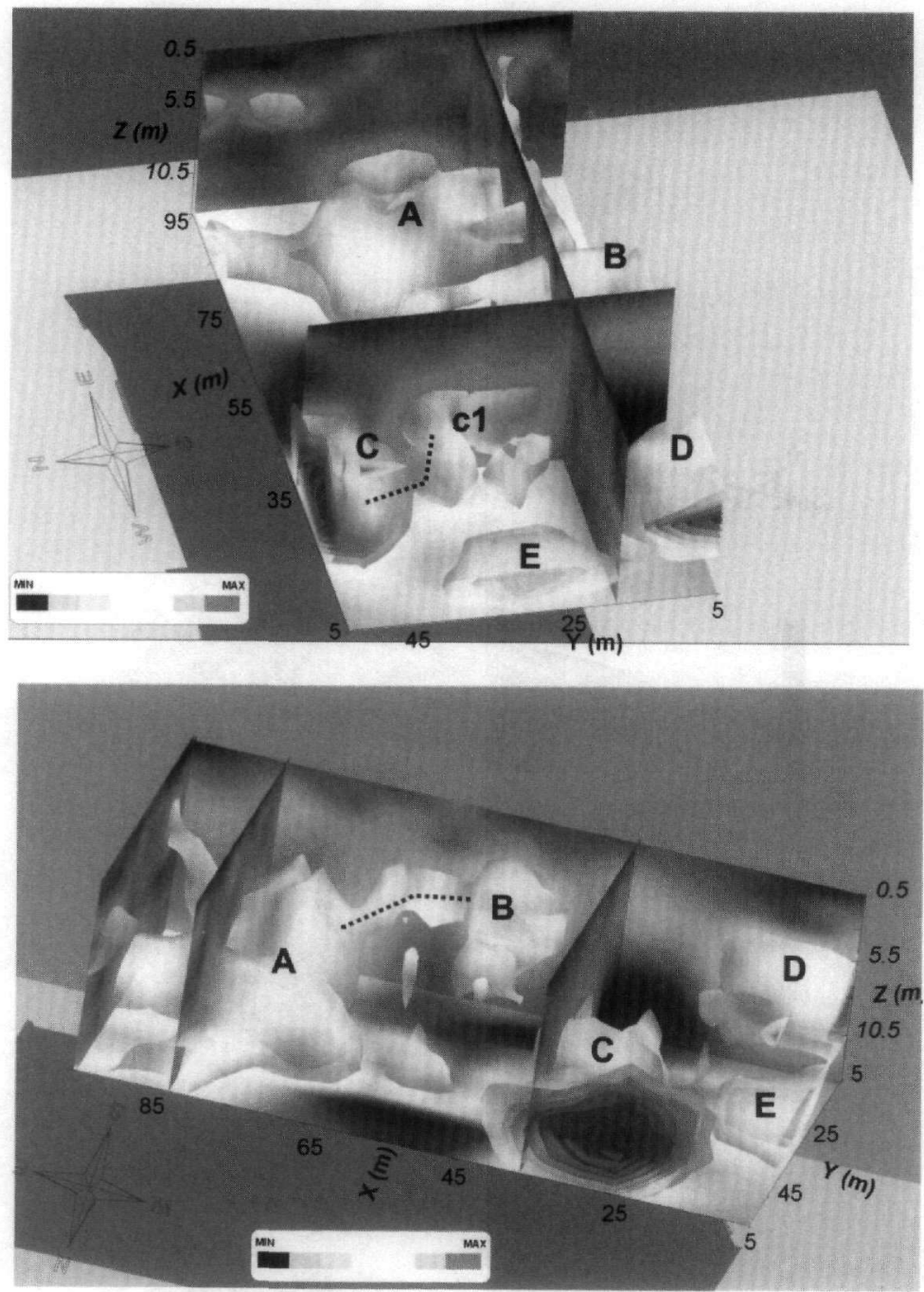

Figure 7-3D visualization of the high resistivity areas. Targets are marked with letters A-E

D: It is located at the South-West corner of the grid. It is longer than 10 meters to the East-West direction and about 10 meters to North-South direction. Its depth is at 7 meters and has a height of about 4 meters.

$\mathrm{E}$ : It is located at the west side of the grid. Its dimensions are $15 \mathrm{~m}(\mathrm{NS})$ and $10 \mathrm{~m}(\mathrm{EW})$ and it seems to continue to the West. The depth of the ceiling is about 10 meters and the height is 2-3 meters. It is possible that it communicates with the structure $\mathrm{D}$.

\section{Conclusions}

The applied methodology was successful in locating the known cave. This not only verified the suitability of the ERT into mapping the cave but also helped us to calibrate and interpret the results. This is generally extremely important in resistivity prospecting at areas of high resistivies such as the surveyed one. In this cases often there is ambiguity in interpreting high resistivity 
anomalies which can be equally attributed either to voids or to "healthy" (lees fractured) blocks of the bedrock.

Based on the results of the calibration measurements that have been conducted at the area of the known cave, the detection of targets, possibly corresponding to voids was made possible. Actually some of them were verified by observations within the cave. Possible further application of other geophysical techniques will further increase the reliability of the interpretations. Overall ERT proved a useful and low cost technique to map the cave.

\section{References}

Cardarelli, E., Marrone C., and Orlando L., 2003. Evaluation of tunnel stability using integrated geophysical methods, Journal of Applied Geophysics, 52 (2-3), 93-102.

Chamberlain, A.T., Sellers, W., and Proctor, C., 2003. Cave detection in limestone using ground penetrating radar. Journal of Archaeological Science, 27. (10), 957-964 OCT 2000.

El-Qady, G., Hafez, M., and Abdalla, M., 2005. Imaging subsurface cavities using geoelectric tomography and ground-penetrating radar, Journal of Cave Karst studies, 67 (3), 174-181.

Gibson, P.J., Lyle, P., and George, D.M., 2004. Application of resistivity and magnetometry geophysical techniques for near-surface investigations in karstic terranes in Ireland, Journal of Cave Karst studies, 66 (2), 35-38.

Leucci, G., and De Giorgi, L., 2005. Integrated geophysical surveys to assess the structural conditions of a karstic cave of archaeological importance, Nat. Hazard Earth Sys., 5 (1), 17 22.

McCann, D.M., Jackson, P.D., and Culshaw, M.G., 1987. The use of geophysical surveying methods in the detection of natural cavities and minshafts, Quarterly Journal of Engineering Geology, 20, 59-73.

Madrussani, G., Böhm, G., Vesnaver, A., and Schena, G., 1999. Tomographic detection of cavities in mines for acid drainage control, European Journal of Environmental and Engineering Geophysics, 3, 115-130.

Nath, SK, 2004. Cross-hole seismic tomography - A geophysical tool for detecting mine galleries, Nat. Acad. Sci. Lett., 27 (3-4), 77-94.

Piro, S., Tsourlos, P., and Tsokas, G., 2001. Cavity detection employing advanced geophysical techniques: a case study, European Journal of Environmental and Engineering Geophysics, 6, 3-31.

Santos, F., and Afonso, A., 2005. Detection and 2d modelling of cavities using pole-dipole array, Environmental Geology, 48 (1), 108-116.

Styles, R., McGrath, R., and Thomas, E., 2005. The use of microgravity for cavity characterization in karstic terrains, Q J Eng. Geol. Hydrog, 38, 155-169

Tsourlos, P., 1995. Modelling, interpretation and inversion of multi-electrode resistivity survey data, D.Phil. Thesis, University of York, U.K.

Tsourlos, P., Szymanski, J., and Tsokas, G. 1998. A smoothness constrained algorithm for the fast 2-D inversion of DC resistivity and induced polarization data, Journal of the Balkan Geophysical Society, 1, 1, 3-13.

Zhou, QY, Matsui, H, and Shimada, J., 2004. Characterization of the unsaturated zone around a cavity in fractured rocks using electrical resistivity tomography, Journal of Hydrological Research, 42, 25-31. 